\title{
Degree of Possession and Practicing of Mathematics Teachers in the Basic Stage of Basic Education Principles in Their Teaching from Their Point of View
}

\author{
Awad Mufleh Shihab Alkhazam ${ }^{1}$ \\ ${ }^{1}$ Curriculums and Teaching Department, Faculty of Educational Sciences, The World Islamic Sciences and \\ Education University, Tabarbour, Amma, Jordan \\ Correspondence: Awad Mufleh Shihab Alkhazam. E-mail: awad_kaldy@yahoo.com
}

Received: October 5, 2018 Accepted: October 28, $2018 \quad$ Online Published: November 29, 2018

doi:10.5539/ass.v14n12p243 URL: https://doi.org/10.5539/ass.v14n12p243

\begin{abstract}
This study aimed at recognizing the degree of possession and practicing mathematics teachers in the basic stage of basic education principles in their teaching from their point of view. Is there a connective relationship between the degree of possessing of basic education principles and the degree of practicing them. The sample of study consisted of (32) mathematics teachers in the basic stage. The instrument of study covered a questionnaire consisted of (14) items. The validity of the questionnaire and its reliability had been assured; the possession reliability coefficient amounted to $(0.90)$ and $(0.88)$ for practice. The researcher employed the appropriate statistical techniques, such as arithmetic means and standard deviations, and Pearson's Correlation coefficient for examining the strength of relationship between both degrees of possession and practice. Results of study deduced that mathematics teachers in the Basic stage possess Basic Education principles, as a whole, at a medium degree, where it was conspicuous that they possess (4) principles of the Basic Education principles at a high degree, (5) principles at a medium degree and (5) principles at a little degree, meanwhile mathematics teachers in the Basic stage practice the Basic Education principles as a whole at a medium degree too, where it was cleared that they practice (4) principles of the Basic Education principles at a great degree, (5) principles at a medium degree and (5) at a little degree. Results also deduced existence of positive connection, stab, (5) principles at a medium degree and (5) at a little degree. Results also deduced existence of positive connection, statistically significant at $(\alpha \leq 0.05)$ between the degree of possessing the Basic Education principles and the degree of practicing them at $\bar{m}$ athematics teachers in the Basic Stage.
\end{abstract}

Keywords: basic education principles, degree of possession and practicing, mathematics teachers, basic stage

\section{Introduction}

Basic Education Principles are considered from the fundamentals of education of the teacher and from the core and basics of the teacher in general and the mathematics teacher in particular. There are numerous general principles emerging from different theories, to which the teacher can reach and guide by at performing the summer teaching process for his work to be more effective and through which the hoped educational objectives can be achieved.

Teaching is also considered the applied side of education or one of its forms and the most important of it, it is a system having its three elements represented in the teacher, the literature and the studying curriculum, and in return we may find that the teaching process may occur, but the learning process did not occur to some students, or may occur, but at a weak form, does not fit the exerted effort, time and expenditures (Al-Helah, 2007).

There are philosophical, social and psychological fundamentals the teaching leans upon, and from these fundamentals, specific visualizations of numerous basic matters in teaching, emerged to confront to lay practical solutions of them, as called these visualizations the term "introductions of teaching" and had emerged of each great introduction other introductions connected with it and its basic outbursts, differ from it at some branching things. That refers to difference of points of view of psychologists (Al-shebli, 2000).

\section{Theoretical Framework}

Great Teaching Introductions: This introduction includes three primary introductions, they are:

Cognitive introductions: they are introductions concern about the content, especially what relates with its 
organization, from their forms: introduction of the studying subject that greatly concerns about the content where its props are represented in explanation performed by the teacher and school text, the thing that the learner is entrusted to study the school text and work to learn its content by heart without observing his needs. This is considered a side of weakness in it.

From its forms also is the structure of science introduction which is considered a qualitative development of the former figure (introduction of the studying subject) that concerns with studying the logical structure of the basic subjects from principles, generalizations theories concerning one of sciences for each science has a particular structure, and concentrates on developing instruments, means and techniques employed by researchers in science, and from representatives of this introduction is Broner and Helda Taba (Furaj, 2009).

\section{Individual and Social Introductions:}

They are the introductions that greatly concern about the individual, who is part of the community from part of sentimental experiences, intellectual needs and trends from their tributary introductions or their forms.

\section{Personal introduction:}

It is the introduction that mainly concerns about the human with what relates with cognitive and emotional characteristics, drives, trends and the general personal traits, for those characteristics have great significance in integration of his personality and continuing his learning at school and life, from representatives of this introduction is Karl Rogers and Maslow.

Introduction of individual's needs:

It is the introduction that its pioneers view that the program of the studying subjects should spring up from students' concerns and direct daily needs as they express them. What this program demands is both the student and the teacher to share in planning the program, and students perform the work alone and in groups. This introduction also concentrates on making the suitable spheres available to grow ego at students.

\section{Introduction of Speculative Thinking:}

Pioneers of this introduction view that every individual should speculate in his beliefs and subdue them to application by the scientific technique as far as possible, that is see if they were with significance and benefit to catch or not. The most prominent pioneers of this introduction is Decartes, Dewe and Beacon.

\section{The Social Introduction:}

Pioneers of this introduction view that education is life and this introduction concerns with environments and the social institutions like the school through which information is provided to students at a social sphere similar to an extent the social sphere available outside the school. From the forms of this introduction is school as a social environment and a social institution. From the most prominent pioneers of this introduction is John Dewe (Naser, 2006; Zeitoun, 2001).

\section{Introductions of Control:}

They are the introductions that govern the educational operations, highly governing. Also it gives a particular significance to the operation of the circulation readiness and its planning. From their subsidiary introductions or forms each of activity introduction, systems introduction, and the behavioral introduction (Al-Adwan \& Al-Hawamdeh, 2011).

Basic principles of Education:

Great teaching introductions excreted numerous general principles, that the teacher may follow and instructed by in education, and from these principles, are the following:

\section{Derived Principles from the Cognitive Introductions:}

They are the principles derived from the Geshtalt Theory in Psychology that concentrates on the form and concerns with the whole system of education, and assurers numerous principles most significant of them:

- Principle of organizing cognition:

This principle indicates to the teacher's transfer to cognition, from the simple to the compound, that mostly is from the imposed parts, meaningless to meaningful totals.

- Principle of concentration on understanding:

This principle indicates that the teacher should concentrate on learning by understanding, that is because it considered more pliable and staying to transfer its effect from one domain to another. 
- $\quad$ Principle of specifying purposes:

This principle indicates to the significance of specifying the purposes by the teacher, because they increase his motivation to learning.

- $\quad$ Principle of transferring from approaching thinking to remoting thinking:

This principle indicates to that the approaching thinking leads to logical correct answers, but the remoting thinking leads to innovated solutions of problems, or getting new valuable products.

- Principle of Feedback:

This principle indicates to that the cognitive feedback works to support the correct cognition, and also supervises the process of correcting the mistaken education (Al-Helah \& Mar'i, 2015; Al-Ali, 2006).

\section{Derived Principles from the Individuals and Social Introductions:}

They are the derived principles from Psychology and its social theories related with individuals and characteristics of their growth, abilities, beliefs, culture, drives, inclinations, their psychological state and their cooperation and assures numerous principles, most significant are:

- Principle of observing the abilities of the learner:

This principle indicates to the necessity of preparing the appropriate circumstances for the learner's abilities, that is because the learner's abilities are considered a significant element in the process of learning for the learner.

- Principle of observing characteristics of growth:

This principle indicates to the necessity of early making environmental opportunities available for the learner, agree with the appearance and crystallization of his growth characteristics, where delay in saving them leads to their slenderness and absence sometimes.

- Principle of cultural factors:

This principle indicates to the leaner's affection in his education to a far-extent affection with culture acquired by the teacher from the community in which he lives.

- $\quad$ Principle of making drives, or motives available:

This principle indicates to the necessity of making educational stands available working on irritating the motivation of all learners to make them learn and motivate them on, observing the individual differences in submitting those educational stands for learners.

- Principle of availability of the social sphere:

This principle indicates to the significance of the social sphere and its effect in assisting the learner on improving education, that demands from the teacher availability of a sphere of tolerance and cooperation among students and go far away from the negative, overcoming and isolational sphere of competition that leads to dislikeness of learning and negatively affects its results.

- $\quad$ Principle of learning affection with anxiety:

This principle indicates that the level of anxiety at the teacher has its effect in the excitement that encourages learning, and this excitement may assists learning, or hinders it, for it has been cleared that low anxiety has its use in education, meanwhile high anxiety hinders it (Al-Helah \& Mar'i, 2015; Al-Helah, 2002).

\section{Derived Principles from control introductions:}

They are the principles derived from attributes of the scientific phenomenon that is being applied on education considered acting applied science all by itself and derived from the behavioral theories, reinforcing theory, and activity introduction.

It assures the following principles:

- Moving principle with learning by logical graduation:

This principle indicates to what the organizational theory in education related with the logical connection concentrates among the constituents of the system, for this principle is taken from the behavioral theory, that should design any educational program at a correlated series logically at a graduating form in its steps to have an excess to the objectives of the educational program.

- $\quad$ Principle of learning movement from sensory excitatives to the mere concepts:

This principle indicates to coupling the necessity of practicing things themselves by paraphrasing and employing 
it at other similar stands, that is for the mental formation of the concept, and this is what the activity of introduction assured.

- Principle of reinforcement:

This principle indicates to the necessity of reinforcing the job of the learner to lead to fix the correct learning at him, strengthening it and correcting the track of error in it.

This is upon which the psychologist (Skinner) concentrated in the theory of reinforcement, that has the great effect on work results (Shihatah, 2004; Mar'i \& Al-Helah, 2015).

Results of study Al-Gamsh (2013) indicated to that the level of teachers of gifted students practice of effective teaching dimensions was at a medium degree. Results also showed non-existence of differences with statistical significance between male and female teachers in estimating efficiencies related with the three dimensions of study instrument. Results of study also indicated to non-existence of differences with statistical significance among teachers of gifted students in the degree of their practice of effective teaching dimensions ascribed to each of years of experience and the teachers' scientific qualification on the instrument of study as a whole.

And Results of study Ibrahim and Abdelkareem (2011) showed that teachers of the preparatory stage and its female teachers practice the skill of submitting the studying subject in a good way through connecting the present lesson with the previous one and illustrating the main ideas at the beginning of the lesson. Results also uncovered fewness of using the educational means by male and female teachers of the preparatory stage and also showed fewness of their using the external readings related with the subject of the school text. While results disclosed existence of differences with statistical significance at the degree of their practice of effective teaching principles ascribed to the variable of specialization and were for the interest of the scientific. Meanwhile it cleared nonexistence of difference with statistical significance in the degree of their practice of effective teaching principles ascribed to the variable of service.

Also Results of study Al -Jboori (2006) showed that fewness of employing the educational means by both male and female teachers of Arabic in classes of special education, concerning category of slow-learners, while results did not show existence of differences statistically significance in responses of the sample of study in employing skills of effective education skills ascribed to the variable of sex. Meanwhile results showed existence of differences with statistical significance in responses of the sample of study to the variable of scientific qualification for the interest of both male and female teachers obtaining the Bachelor Degree.

And also Results of study Al-Sughayer (2002) showed that the average of statements of effective teaching concepts at the sample of study drops at promotion across stages of growing teaching in general. Results of study also showed non-existence of differences statistically significant between teachers and supervisors at both pivots of teaching basics and teaching tasks, meanwhile results showed differences statistically significant in teaching between supervisors and teachers for the interest of supervisors.

As Results of study Munawer (2001) showed that the degree of practicing principles of effective teaching from the male and female teachers of physical education point of view was situated within the middle. While results did not show any statistically significant differences among estimations of teachers of physical education of their practice to the effective teaching due to both variables of sex and years of experience. Results also showed existence of differences with statistical significance for those who obtain the higher diploma in education, above the bachelor degree for the interest of teachers.

Meanwhile Results of the study Al-Smadi and Al-Nahar (2001) showed that availability of the general skills related with planning, teaching and evaluation at a good form at teachers of special education. Results also showed existence of difference with statistical significance in level of mastering each of (planning, carrying out the lesson, and evaluation) efficiencies in accordance with the variable of sex, for the interest of female teachers. Results also showed to existence of difference with statistical significance in level of mastering each of efficiencies of (planning, carrying out the lesson, and evaluation) in accordance with the variable of qualification for the interest of those obtaining the bachelor degree. Finally, results showed existence of difference with statistical significance in level of mastering skills of teaching in accordance with the variable of experience for the interest of those whose experience exceeds (7) years. While results did not show differences with statistical significance on both dimensions of planning and evaluation or the total degree ascribed to the difference of experience level.

And also Results of study Al-Ga'oud and Abu Isba' (1997) showed that the degree of teachers' practice of effective education principles was medium in accordance with teachers' estimations of themselves and their supervisors. Results also showed that there are differences statistically significant among estimations of 
supervisors and teachers for the interest of teachers with exception of their estimations on the eighth domain related with developing skills, values and trends and the differences were for the interest of teachers holding a bachelor and less, while results did not show differences statistically significant among estimations of supervisors and teachers according to their behavioral scientific qualification (bachelor, high diploma, and master degree and more). Also results did not show any differences with statistical significance ascribed to experience of teachers.

\section{Objectives of Research}

Due to significance of Basic Education Principles in the teaching process and its effectiveness, that proved the theoretical literature, especially the Educational Psychology assuring it and the necessity of teachers' possession of it, and their practice of it in the classroom, for what it has of reflections and great positive effect on students' obtainment. From this point came this study aiming at recognizing the degree mathematics teachers in the Basic Stage possess the Basic Education Principles and the degree of their practice of it at their teaching from their point of view. Through answering the following questions:

1. What is the degree of possession of mathematics teachers in the basic stage of basic educational principles from their point of view?

2. What is the degree of practicing mathematics teachers in the basic stage of basic education principles in teaching from their point of view?

3. Is there a connective relationship between the degree of possessing principles of basic education and the degree of practicing them at mathematics teachers in the basic stage education?

\subsection{Suppositions of Research}

The researcher supposes the following suppositions for this study:

1. Mathematics teachers in the basic stage of the community of study can estimate the degree of their possession of basic education principles and the degree of their practice of them in teaching included in the instrument of study innocently and solemnly.

2. Mathematics teacher in the basic stage who possesses some of basic education principles can practice this some of principles in class teaching.

3. There is enough awareness with basic education principles, necessary for mathematics teachers in the basic stage of the community of study.

\subsection{Significance of Research}

This study originates from the following:

1. Providing a list of the Basic Education Principles necessary for mathematics teachers in the basic stage.

2. It is expected for this study to share in assisting mathematics teachers in the basic stage on developing their teaching performance according to the recommendations deduced by the study from part of possession and practice of basic education principles.

\subsection{Procedural Definitions}

Principles of Basic Education: (Naser, 1996) defined them as "the general principles excreted by the great introductions teaching, by which the teacher can be guided in education".

But the procedural definition: The researcher defines the Basic Education principles in light of procedures of the present research: as a "the group of rules by which the teacher is guided in his teaching and that had to be possessed by the mathematics teacher in the basic stage, and it is supposed to be employed during his class teaching, derived from the great teaching introductions: cognitive, individuals, social and control. Represented in the provided domains and items in the questionnaire, prepared for this study".

Degree of Possessing Principles of Basic Education: It is the degree of the availability of Basic Education principles at the mathematics teacher in the basic stage, measured by the degree laid by the mathematics teacher to himself in the instrument prepared for this purpose.

Degree of Practicing Principles of Basic Education: Means the actual implementation degree using and employing the Basic Education principles in the Basic Stage by the mathematics teacher, he possesses in his teaching, and had been measured by the total degrees estimated by the mathematics teacher to himself during answering the list of Basic Education Principles in the instrument prepared for this purpose.

Teachers of Mathematics in the Basic Stage: They are all mathematics teachers, who teach the subject of 
mathematics in the basic stage through the Second Studying Semester from the year 2017/2018 at schools of Education Directorate Al-Mafraq Governorate Town.

\subsection{Determinants of Research}

1. This study was confined on all male and female mathematics teachers, who teach the subject of mathematics for the Tenth Basic Grade at Public Schools following the Directorate of Education of Al-Mafraq Governorate Town in the Second Semester of the year 2017/2018.

2. This study was confined to the Basic Education principles derived from the three great teaching introductions: cognitive, individual, social and control.

3. The instrument that was used to collect information in this study is prepared by the researcher and due to his knowledge of educational literature and previous studies related with the subject of study. Therefore, the results of study depend on the degree of validity, reliability and its ability to uncover variation among mathematics teachers in the basic stage at their estimation to specify the degree of their possession of Basic Education Principles and the degree of their practicing them from their point of view.

\section{Material and Methods of Research}

Curriculum of research: The researcher employed the descriptive method at the surveying from concordant with the nature of this study.

Community of research and its sample: The community of study consisted of all male and female mathematics teachers, who teach the subject of mathematics in the basic stage at Public Schools following the Directorate of Education of the town of Al-Mafraq Governorate during the Second Studying semester of the year 2017/2018. Their number had amounted to (64) male and female teachers, distributed on (56) Public Schools according to Statistics of Planning Department in the Directorate.

But the sample of study had been chosen by the random racemose method, where the studying class was the choice unit, and all the male and female teachers, who teach the subject of mathematics for the Basic Tenth Grade in the community of study, for their number amounted to (32) male and female teachers chosen by a random method at the rate of $(50 \%)$ of the community of study.

Variables of Research: This study consists of two subordinate variables, they are:

- Degree of possessing the basic education principles by mathematics teachers in the basic stage.

- Degree of practicing the basic education principles by mathematics teachers in the basic stage in teaching.

Instrument of Research:

The researcher did develop the instrument of analogy for this study. It is a questionnaire initially consisted of (20) items distributed on three domains, they are: (derived principles from cognitive introductions), that is through informing and reference to the educational literature related with the subject of this study. The instrument of study consisted of two parts: the first measures the degree of possessing the skill, and the second measures the degree of practicing it. And due to that he depended on - an analogy of fivefold graduation to correct the answer on items, that is to estimate possession of mathematics teachers in the basic stage on the right side of the questionnaire, and the same fivefold estimation on the same ladder, that is to estimate degrees of mathematics teachers in the basic stage on the left side practice of the same questionnaire. The researcher asked laying the sign $(\mathrm{X})$ under one degree of the five degrees they are: (very high degree and has five degrees, with high degree and has four degrees, at a medium degree and has three degrees, with little degree and has two degrees and with very little degree and has only one degree).

Validity of the instrument: to make sure of the validity of the instrument of study, it had been presented to a group of arbitrators specialized in the domain of curriculums and methods of teaching, psychology, and sociology from the teaching staff members at universities, educational supervisors and experts. Their number had been (20) experts and teaching staff members. They were asked to show their opinions about the validity of the questionnaire items and their domains in measuring what was laid to be measured, from part of formulation, clarity, organization, addition and omission. Since the number of arbitrations is (20), the items that are by (15) members of the university teaching staff and educational experts that are at the rate of $75 \%$ meanwhile items that obtained a fewer rate of this were removed, and in light of arbitrators' opinions, the formulation of items that need formulation were repeated, and the weak unfit items were omitted. And due to the majority of arbitrators' opinions six items of the questionnaire were omitted and removed and amended the formulation of two items of them, and so the instrument of study with its final form became consisted of (14) items. 


\section{Reliability of the instrument:}

For the reliability of instrument, the researcher did apply it an a sample from outside the sample of study by the method of test and retest, where the application of instrument had been done on (30) male and female teachers for the first time from outside the sample of study. Then the questionnaire was applied for the second time after two weeks from the first time on the same sample, and it had been made sure of reliability of the instrument according to the reliability coefficient for each domain and for all domains and the total of the reliability coefficient of the instrument at the side of possession and practice....it is $(0.90,0.88)$ consecutively, and it is accepted for the purpose of this study, as shown in the Table 1.

Table 1. Value of reliability coefficient for each of the study instrument domains at the side of possession and practice

\begin{tabular}{cccc}
\hline No. & Domain & $\begin{array}{c}\text { Value of Reliability Coefficient at } \\
\text { the Side of Possession }\end{array}$ & $\begin{array}{c}\text { Value of Reliability Coefficient } \\
\text { at the Side of practice }\end{array}$ \\
\hline $1 \quad$ & $\begin{array}{c}\text { Domain of Derived Principles from the } \\
\text { Cognitive Introductions }\end{array}$ & .83 & .80 \\
2 & $\begin{array}{c}\text { Domain of Derived Principles from the } \\
\text { Individual and Social Introductions } \\
\text { Domain of Derived Principles from the } \\
\text { Control Introductions }\end{array}$ & .92 & .89 \\
3 & $\begin{array}{c}\text { Total Reliability Coefficient of the Instrument } \\
\text { Then }\end{array}$ & .86 & .86 \\
\hline
\end{tabular}

\section{Procedures of carrying out the Research:}

After that the community of study had been specified, the researcher did distribute and apply the instrument of study (questionnaire) all by himself on the individuals of the sample of study amounting to (32) male and female teachers, and collected the instrument preparing for its statistical processing.

\section{Statistical Possessing:}

To process data he collected for this purpose of study, the researcher employed the group of statistical parcel (SPSS) and to answer both questions, one and two related with the degree of possession and practice by mathematics teachers in the basic stage from their point of view, arithmetic means and standard deviations for all items of the questionnaire for both sides of possession and practice. Standard deviations had been counted at the level of items and were put in order at a descending form.

And to answer the third question related with disclosing the relationship between the degree of possessing principles of basic education at mathematics teachers in the basic stage and the degree of their practice in teaching. Pearson's connection coefficient had been employed, where connection coefficients were counted between both degrees of possession and practice at individuals of study sample responses as a whole.

To specify the degree of possession and practice, the researcher confirmed the following standard due to the equation:

Extent of scale classes.......(highest degree for the scale...lowest degree for the scale) divided on the required number of classes. Thus the extent of the scale is $(5-1) / 3=1.33$ and so the researcher confirms the following standard:

1. Degree of possession/ practicing the principles at a little form (few) if the average was located between (1-2.33).

2. Degree of possession/ practicing the principle at a medium form if the average was located between (2.34-3.67).

3. Degree of possession/ practicing the principle at a high form if the average was located between (3.68-5).

\section{Results of Research and Discussion}

Results related with answering the first question what is the degree of possessing Basic Education principles by mathematics teachers in the basic stage from their point of view?

To answer the first question, the arithmetic means and standard deviations and ranks were counted for estimations of mathematics teachers in the basic stage, and principles had been counted descending according to arithmetic settings of each domain of them. Table 2 illustrates the arithmetic means, standard deviations and ranks for each principle descending put in order. 
Table 2. Arithmetic means, standard deviations and rank of degree of possessing Basic Education principles within each domain descending put in order

\begin{tabular}{|c|c|c|c|c|c|}
\hline $\begin{array}{l}\text { Item } \\
\text { No. }\end{array}$ & Rank & Domains and Principles & $\begin{array}{l}\text { Arithmetic } \\
\text { Mean }\end{array}$ & $\begin{array}{l}\text { Standard } \\
\text { Deviation }\end{array}$ & $\begin{array}{l}\text { Degree of } \\
\text { Possession }\end{array}$ \\
\hline \multicolumn{6}{|c|}{ Firstly: Domain of derived principles from the cognitive introductions } \\
\hline 4 & 1 & $\begin{array}{l}\text { Principle of organizing cognition and transfer it from simple to } \\
\text { compound }\end{array}$ & 4.18 & .67 & High \\
\hline 3 & 2 & $\begin{array}{l}\text { Principle of concentration on understanding to last learning } \\
\text { and its effect movement }\end{array}$ & 3.85 & .73 & High \\
\hline 5 & 3 & $\begin{array}{c}\text { Feedback principle that supports correct cognition \& } \\
\text { correcting mistaken education }\end{array}$ & 3.01 & .58 & Medium \\
\hline 1 & 4 & Principle of specifying goals to be an incentive for learning & 2.76 & .62 & Medium \\
\hline 2 & 5 & $\begin{array}{l}\text { Principle of movement from approaching thinking to } \\
\text { separating one. }\end{array}$ & 2.30 & .84 & Few \\
\hline \multicolumn{3}{|c|}{ Domain of derived principles from the cognitive introductions as a whole. } & 3.22 & .69 & Medium \\
\hline \multicolumn{6}{|c|}{ Secondly: domain of derived principles from the social and individual introductions. } \\
\hline 8 & 6 & Principle of observing abilities of learner & 4.00 & .51 & High \\
\hline 11 & 7 & Principle of observing characteristic traits of growth & 3.16 & .65 & Medium \\
\hline 7 & 8 & Principle of cultural factor & 2.40 & .89 & Medium \\
\hline 6 & 9 & Principle of social atmosphere availability. & 2.06 & .60 & Few \\
\hline 9 & 10 & Principle of saving the social atmosphere. & 2.03 & .78 & Few \\
\hline 10 & 11 & Principle of learning affected by anxiety. & 1.92 & 1.01 & Few \\
\hline \multicolumn{3}{|c|}{$\begin{array}{l}\text { Domain of the derived principles from the individual and social introductions as } \\
\text { a whole }\end{array}$} & 2.60 & .74 & Medium \\
\hline \multicolumn{6}{|c|}{ Thirdly: Domain of derived principles from control introductions } \\
\hline 14 & 12 & Movement principle in learning by logical graduation & 3.84 & .77 & High \\
\hline 12 & 13 & $\begin{array}{l}\text { Principle of learning movement from the sensual affections to } \\
\text { pure concepts. }\end{array}$ & 2.96 & .69 & Medium \\
\hline 13 & 14 & Principle of reinforcement to fix the correct and correct error. & 2.28 & .82 & Few \\
\hline \multicolumn{3}{|c|}{ Domain of the derived principles from introductions of control as a whole. } & 3.03 & .76 & Medium \\
\hline \multicolumn{3}{|c|}{$\begin{array}{l}\text { Total degree of possessing principles of basic educational for the three domains } \\
\text { as a whole. }\end{array}$} & 2.91 & .73 & Medium \\
\hline
\end{tabular}

Data of Table 2 indicate that the degree of possession by mathematics teachers in the basic stage of basic education principles from their point of view to domains of the instrument as a whole was at a medium degree, where the arithmetic mean for all the three domains of the instrument amounted (2.91) with a standard deviation (.73). Data of the table connected with putting items of the first domain in order (domain of the derived principles from the cognitive introductions) and according to the degree of significance that the item No. (4) had come in the first rank, wording on principle of organizing cognition and move it from simple to compound "had occupied the first rank in between items of this domain, where the value of the arithmetic mean of this item amounted to (4.18) at a high degree. And in the second rank came the item No. (3) that words on" principle of concentrating on understanding for the remaining of learning and movement of its effect at an arithmetic mean (3.85) and at a high degree too. The fewest principle of possession within this domain and in the last rank is the item No. (2) that words on "principle of movement from the approaching thinking to the separating one", at an arithmetic mean (2.30) at a low degree. It is also noticed generally that the degree of possessing this domain as a whole was at a medium degree. For the arithmetic mean amounted to the degree of possessing items of this domain as a whole (3.22). Data of the table related with organizing items of the second domain, connected with possessing the derived principles from the individual and social introductions and due to degree of significance that the item No. (8) had come in the first rank that words on "principle of observing the learner's abilities" at an arithmetic mean amounting to(4.00) and at a high degree. Also the item No. (11) came in the second rank, that words on "principle of observing characteristic traits of growth" at an arithmetic mean (3.16) at a medium degree. meanwhile the item No. (10) obtained the last rank within this domain, that words on "the principle of the learner's affection with anxiety" at an arithmetic mean (1.92) at a low degree. It is generally noticed as well that degree of possessing this domain as a whole was medium, for the arithmetic mean amounted to the degree of possessing items of this domain as a whole (2.60). Finally data of the table related with organizing items of the 
third domain, connected with possessing the derived principles from control introductions and according to the degree of significance that the item No. (14) had come in the first rank and words on "principle of moving in learning with logical graduation" at an arithmetic mean amounts to (3.84) at a high degree. Also the item No. (12) came in the second rank, that words on "principle of moving learning from sensual affection into the pure concepts" at an arithmetic mean (2.96) at a medium degree, meanwhile the item No. (13) within this domain obtained the last rank that words on "principle of reinforcement to fix the correct and correct error" at an arithmetic mean (2.28) at a low degree. And generally noticed that the degree of possessing this domain as a whole was at a medium degree, where the arithmetic mean amounted to degree of possessing items of this domain as a whole (3.03). The researcher ascribes the reason in that to mathematics teachers receiving, especially the new of them, training courses relate with basic education principles due to its significance in achieving effective education to students and raising the level of their obtainment, where obtaining tests for teachers at the end of these courses are concluded. We also confess that there are individual differences among teachers in the degree of possessing these principles, some of them possesses it highly or greatly, and some possesses it at a medium degree and others possess it at a weak or little form. The researcher also ascribes that to the subjects of the school text mostly graduate in giving the information of the concept to students, where it demands the teacher to logically possess that principle to harmony with what is available in front of him in the school text by submitting subjects of the text to students serially or by logical graduation from the simple to the compound. He is the counselor of it. Also we find that activities of the school text are designed to observe the teacher's abilities and the characteristic traits of his growth, so we find that the teacher possesses those principles greatly more than other principles. Also the researcher views that there are some principles related with the approaching thinking, separating and extent of learning affection by anxiety and reinforcement with its different types that are different for the teacher possesses for fewness of domains to be employed in his class stand. Also the researcher ascribes fewness of teachers' possession of these principles that the mathematics teacher did not receive enough training and not reach the stage of understanding it and grasping it well to possess and apply it properly and fewness of practicing it.

Results related with answering the second question: What is the degree of practice by teachers of mathematics in the Basic Stage in their teaching from their point of view?

To answer the second question arithmetic means and standard deviations and ranks to estimations of mathematics teachers in the Basic Stage for the degree of their practice of Basic Education principles were counted. The principles had been descending organized according to the arithmetic means of them. Table 3 arithmetic means and standard deviations and the rank for each skill descending organized.

Table 3. Arithmetic means, standard deviations and ranks to the degree of practicing each of Basic Education principles descending organized

\begin{tabular}{|c|c|c|c|c|c|}
\hline $\begin{array}{l}\text { Skill } \\
\text { No. }\end{array}$ & Rank & Domains and Principles & $\begin{array}{l}\text { Arithmetic } \\
\text { Mean }\end{array}$ & $\begin{array}{c}\text { Standard } \\
\text { Deviation }\end{array}$ & $\begin{array}{c}\text { Degree of } \\
\text { Practice }\end{array}$ \\
\hline \multicolumn{6}{|c|}{ Firstly: Domain of derived principles from the cognitive introductions } \\
\hline 4 & 1 & $\begin{array}{l}\text { Principle of organizing cognition and transfer it from the simple to } \\
\text { the compound }\end{array}$ & 3.96 & .86 & High \\
\hline 3 & 2 & $\begin{array}{l}\text { Principle of concentration on understanding to remain learning and } \\
\text { transfer of its effect }\end{array}$ & 3.12 & .61 & High \\
\hline 5 & 3 & $\begin{array}{l}\text { Principle of feedback that supports the correct cognition } \& \text { corrects } \\
\text { the mistaken education }\end{array}$ & 2.74 & .75 & Medium \\
\hline 1 & 4 & Principle of specifying goals to be an incentive for learning & 2.40 & .59 & Medium \\
\hline 2 & 5 & $\begin{array}{c}\text { Principle of transfer from the approaching thinking to the separating } \\
\text { one. }\end{array}$ & 1.48 & 1.02 & Few \\
\hline \multicolumn{3}{|c|}{ Domain of derived principles from the cognitive introductions as a whole. } & 2.74 & .77 & Medium \\
\hline \multicolumn{6}{|c|}{ Secondly: Domain of derived principles from the individual and social introductions. } \\
\hline 8 & 6 & Principle of observing the learner's abilities & 3.75 & .55 & High \\
\hline 11 & 7 & Principle of observing the characteristic traits of growth & 3.00 & .71 & Medium \\
\hline 7 & 8 & Principle of cultural factor & 2.34 & .68 & Medium \\
\hline 6 & 9 & Principle of saving drives of barriers. & 1.92 & .85 & Few \\
\hline 9 & 10 & Principle of saving the social atmosphere. & 1.76 & 67 & Few \\
\hline 10 & 11 & Principle of learning affection by anxiety. & 1.40 & .99 & Few \\
\hline \multicolumn{3}{|c|}{ Domain of derived principles from the individual and social introductions as a whole } & 2.36 & .74 & Medium \\
\hline
\end{tabular}




\begin{tabular}{|c|c|c|c|c|c|}
\hline \multicolumn{6}{|c|}{ Thirdly: Domain of derived principles from the control introductions. } \\
\hline 14 & 12 & Principle of moving in learning with logical graduation & 3.69 & .72 & High \\
\hline 12 & 13 & $\begin{array}{l}\text { Principle of learning movement from the sensual affections to the } \\
\text { pure concepts. }\end{array}$ & 2.53 & .63 & Medium \\
\hline 13 & 14 & Principle of reinforcement to fix the correct and correct the error. & 2.10 & .90 & Few \\
\hline \multicolumn{3}{|c|}{ Domain of the derived principles from introductions of the control as a whole. } & 2.77 & .75 & Medium \\
\hline \multicolumn{3}{|c|}{$\begin{array}{l}\text { The total degree of practicing Basic Educational principles for the three domains as } \\
\qquad \text { a whole. }\end{array}$} & 2.58 & .75 & Medium \\
\hline
\end{tabular}

It is clear from Table 3 that the degree of mathematics teachers in the Basic Stage practice of Basic Education principles from their point of view for domains of the instrument as a whole was at a medium degree, where the arithmetic mean for all domains of instrument the three amounted (2.58) with standard deviation (.75). Data of the table connected with organizing items of the first domain (domain of derived principles from the cognitive introductions) according to the degree of significance indicate that item No. (4) had come in the first rank, that words on "principle of cognition organizing and moving it from the simple to the compound" had occupied the first rank among items of this domain, for the value of the arithmetic mean of this item amounted (3.96) and a high degree. Also, item No. (3), that words on "Principle of concentration on understanding for the remaining of learning and transference of its effect" at an arithmetic mean (3.12) and a high degree too. The fewest of principles in practice within this domain and in the last rank is the item No. (2), that words on "principle of transference from the approaching thinking to the separating one", at an arithmetic mean (1.48) and with a little degree. And generally it is noticed that the degree of mathematics teachers practice in this domain as a whole was at a medium degree, where the arithmetic mean amounted to (2.74) of the degree of mathematics teachers practice of this domain as a whole. Also data of the table related with organizing items of the second domain connected with practicing the derived principles from the individual and social introductions and due to the degree of significance indicated that item No. (8) has come in the first rank and words on "principle of observing abilities of the learner" at an arithmetic mean amounting (3.75) with a high degree. Also item No. (11) came in the second rank, that words on "principle of observing the characteristic traits of growth at an arithmetic mean (3.00) and at a medium degree, while the item No. (9) obtained the last rank within this domain, that words on "principle of learning affection by anxiety at an arithmetic mean (1.40) and a little degree. It is also generally noticed that the degree of mathematics teachers practice of this domain as a whole was at a medium degree too, where the arithmetic mean of possessing items of this domain as a whole (2.36). Finally data of the table related with organizing items of the third domain connected by practicing the derived principles from control introductions and due to degree of significance indicate that the item No. (14) had come in the first rank, that words on "principle of moving in learning with logical graduation" at an arithmetic mean (3.69) and at a high degree. The item No. (12) that words on "principle of learning movement from sensual affections into the pure concepts" at an arithmetic mean (2.53) and at a medium degree, came at the second rank, while the item No. (13) within this domain obtained the last rank that words on "principle of reinforcement to fix the correct and correct the error" at an arithmetic mean (2.10) and a little degree. And it is also generally noticed that the degree of possessing this domain as a whole was a medium degree, where the arithmetic mean amounted to degree of possessing items of this domain as a whole (2.77).

The researcher ascribes that to existence of a standard from evaluating the teacher's performance standards during the class stand by the school master and the educational supervisor relates with observing Basic Education principles in teaching, that the teacher adheres to employ, apply, and practice in the classroom to obtain a high evaluation from his master and educational supervisor, who may share in his promotion and avoid the educational enquiry, but degree of teachers' practice of these principles from high to medium to little according to degree of their possession of each principle, or less than that, as it is clear in the answer of the first question, for it is not logical for the teacher to practice a principle greatly, meanwhile we find him possess it at a little form, but the vice-versa may occur. So the researcher has noticed that all values of arithmetic means to the degree of practice are all a little less than the degree of possession. This in the researcher's opinion agrees the logic, because 'the loser of a thing does not give it', and teachers may differ in the degree of their practice to those principles due to individual differences among them.

To answer the third question Pearson's Connection Coefficient had been counted, where connection coefficients were counted between degrees of possession and practice at individuals of study sample responses as a whole, the Table 4 clears that. 
Table 4. Pearson's Connection Coefficient to connection coefficients between both degrees of practice and possession of the sample of study

\begin{tabular}{|c|c|c|c|c|c|}
\hline \multirow[b]{2}{*}{ Degree of Possession } & & \multicolumn{3}{|c|}{ Degree of Practice } & \multirow[b]{2}{*}{ Total } \\
\hline & & $\begin{array}{l}\text { Domain of Derived } \\
\text { Principles from } \\
\text { Cognitive } \\
\text { Introductions }\end{array}$ & $\begin{array}{l}\text { Domain of Derived } \\
\text { Principles from } \\
\text { Individual and } \\
\text { Social Introductions }\end{array}$ & $\begin{array}{l}\text { Domain of Derived } \\
\text { Principles from } \\
\text { Control } \\
\text { Introduction }\end{array}$ & \\
\hline \multirow{3}{*}{$\begin{array}{l}\text { Domain of Derived } \\
\text { Principles from } \\
\text { cognitive } \\
\text { introductions }\end{array}$} & $\begin{array}{c}\text { Connection } \\
\text { Coefficient (R) }\end{array}$ & 0.96 & 0.86 & 0.88 & 0.90 \\
\hline & Significance Level & 0.00 & 0.00 & 0.00 & 0.00 \\
\hline & Number & 32 & 32 & 32 & 32 \\
\hline \multirow{3}{*}{$\begin{array}{l}\text { Domain of Derived } \\
\text { Principles from } \\
\text { individual \& social } \\
\text { Introductions }\end{array}$} & $\begin{array}{c}\text { Connection } \\
\text { Coefficient (R) }\end{array}$ & 0.83 & 0.94 & 0.82 & 0.86 \\
\hline & Significance Level & 0.00 & 0.00 & 0.00 & 0.00 \\
\hline & Number & 32 & 32 & 32 & 32 \\
\hline \multirow{3}{*}{$\begin{array}{l}\text { Domain of Derived } \\
\text { Principles from } \\
\text { Control Introductions }\end{array}$} & $\begin{array}{c}\text { Connection } \\
\text { Coefficient (R) }\end{array}$ & 0.82 & 0.85 & $0 / 97$ & 0.88 \\
\hline & Significance Level & 0.00 & 0.00 & 0.00 & 0.00 \\
\hline & Number & 32 & 32 & 32 & 32 \\
\hline \multirow{3}{*}{ Total } & $\begin{array}{c}\text { Connection } \\
\text { Coefficient (R) }\end{array}$ & 0.87 & 0.89 & 0.82 & 0.88 \\
\hline & Significance Level & 0.00 & 0.00 & 0.00 & 0.00 \\
\hline & Number & 32 & 32 & 32 & 32 \\
\hline
\end{tabular}

Results of statistical analysis provided in Table 4 indicated that both connection coefficients among degrees of possession by mathematics teachers in the Basic Stage of Basic Education principles and degree of their practice for these principles was high and positive amounted (0.88), that means $\rightarrow$ relationship between both degrees of possession and practicing is strong and positive, this means the more the degree of possession increased by mathematics teachers in the Basic Stage of the Basic Educations principles the degree of his practicing it increased, the guide to correctness of this deduction is that principles came in the first ranks or the last at items of study instrument to talk about the degree of possession by mathematics teachers in the Basic stage of these principles, came at the same ranks at talk about their practice of them too. The researcher ascribes that to that mathematics teachers employ their theoretical knowledge related with principles of Basis Education in practicing and practical applying of them at their teaching in a correlative form. Also the researcher ascribes that to the necessity of teachers' practicing application of Basic Education principles because they are one item of evaluating the teacher's performance in the classroom.

\section{Conclusion of Research}

This study aimed at recognizing the degree of possession and practicing of mathematics teachers in the basic stage of basic education principles in their teaching from their point of view, and Is there a connective relationship between the degree of possessing the principles of basic education and the degree of practicing them The results of the research showed that the mathematics teachers in the basic stage possess and practice the basic education principles to a medium degree . Research recommendation the need to train Mathematics teachers on the principles that they have acquired (little). Results also deduced existence of positive connection, statistically significant at $(\alpha \leq 0.05)$ between the degree of possessing the Basic Education principles and the degree of practicing them at Mathematics teachers in the Basic Stage.

\section{Recommendations}

Through results deduced by this study, the researcher recommends with the necessity of concluding training courses relate with recognizing mathematics teachers in the Basic Stage and training them on possessing of Basic Education principles and following their practice of them in the class stand in particular relating with the following principles:

- Principle of movement from the approaching thinking to the separating thinking as one of the derived principles from the cognitive introductions. 
- The derived principles from the individual and social introductions related with (principle of saving drives, or barriers), (principle of saving the social atmosphere) and (principle of learning affection by anxiety).

- Principle of reinforcement to fix the correct and correct error as one of derived principles from control introductions.

\section{References}

Al-Adwan, Z., \& Al-Hawamdeh, M. (2011). Designing Teaching between Theory and Application. Dar Al-Maseerah for Publication and Distribution, Amman, Jordan.

Al-Ali, I. B. A. (2006). Effective Teaching. Retrieved from http://www.drmosad.com/index

Al-Ga'oud, I., \& Abu Isba', O. (1997). Extent of Teachers Practice of the Subject of History for the Second Secondary Grade to Principle of Effective Education (An Evaluative Study), 12(2), 171-196.

Al-Gamsh, M. N. (2013). Degree of Practicing the Dimensions of Effective Teaching in Jordan. The Journal "Dirasat", University of Jordan, 40(1).

Al-Helah, M. M. (2002). Methods of Effective Teaching and its Strategies. University Text House- Al-Ein, United Arab Emirates (UAE).

Al-Helah, M. M. (2007). Skills of Class-Teaching. Dar Al-Maseerah for Publication and Distribution, Amman, Jordan.

Al-Jboori, F. T. M. (2006). Skills of Effective Education at teachers of Arabic (males \& females) at classes of Special Education and its relationship with some variables. Journal of the Faculty of Basic Education, 3(4), 90-126.

Al-Shebli, I. M. (2000). Effective Education and Effective Learning. Dar Al-Amal for Publication and Distribution, Amman, Jordan.

Al-Smadi, J., \& Al-Nahar, T. (2001). Level of Teachers of Special Education in the State of United Arab Emirates (UAE) Mastering Skills of Effective Education. Journal of Educational Researches Center, 10(19), 193-216.

Al-Sughayer, A. B. M. (2002). Perceptions of Physical Education Supervisors and Teachers of the Effective Teaching Concepts in Light of Concerns Theory. Faculty of Education, King Saud University Retrieved from http://www.fpegalex.org/Arabic/ magazine/ no22/e22-3.doc

Furaj, A. L. (2009). Effective Teaching. Cultural House for Publication and Distribution, Amman, Jordan.

Ibrahim, F., \& AbdelKareem, D. (2011). Extent of practice by male and female teachers of the Preparatory Stage of principles of effective teaching. Journal of the Faculty of Basic Education, 11(1). Al-Moosel University Iraq.

Mar'i, T., \& Al-Helah, M. (2015). General Methods of Teaching (7th ed.). Dar Al-Maseerah for Publication and Distribution: Amman, Jordan.

Munawer, S. M. (2001). Extent of Practicing Principles of effective teaching from the point of view of teachers of physic al education. Journal "Dirasat" for Educational Sciences, (2), 337-354.

Naser, Y. (2006). Methods of Teaching. Damascus University Publications, Damascus.

Shihatah, H. (2004). Basic of Effective Teaching in the Arab World (4th ed.). Egyptian Lebanese House for Publication, Cairo, Egypt.

Zeitoun, H. H. (2001). Designing Teaching Systematism Vision (2nd ed.). World of Books, Cairo.

\section{Copyrights}

Copyright for this article is retained by the author(s), with first publication rights granted to the journal.

This is an open-access article distributed under the terms and conditions of the Creative Commons Attribution license (http://creativecommons.org/licenses/by/4.0/). 